\title{
OS PRINCÍPIOS DA TEORIA DAS RESTRIÇÕES SOB A ÓTICA DA MENSURAÇÀO ECONÔMICA
}

\author{
Autor: Reinaldo Guerreiro \\ Pesquisador da FIPECAFI/FEA/USP
}

\section{1- INTRODUÇÃO}

As idéias de Goldratt sobre gestão industrial e o arcabouço de pensamentos sobre a Teoria das Restrições tem sido difundidos mundialmente.

Nos inícios dos anos 70, em Israel enquanto estudante de Física, Goldratt desenvolveu uma formulação matemática para o planejamento da fábrica de um amigo que produzia gaiolas para aves. Essa formulação tornou-se a base do software OPT (Optimized Production Technology) voltado à programação de produção.

Em 1979, foi constituída a empresa Creative Outupt Inc. com o objetivo de comercializar o software e, como Israel era um mercado restrito, com o tempo foram criadas filiais da empresa em outros países (Inglaterra, Estados Unidos e Holanda). O software foi sofrendo uma série de aperfeiçoamentos a partir da experiência prática proporcionada pela implantação do sistema. Em paralelo à evolução do software, Goldratt foi formalizando um a série de princípios, os quais, no seu conjunto, acabaram construindo o pensamento OPT - Optimized Production Technology, ou seja, a tecnologia da produção otimizada.

$\mathrm{Na}$ segunda metade dos anos 80, nos Estados Unidos da América, Goldratt desenvolveu a Teoria das Restrições (TOC - Theory of Constraints), que pode ser entendida como uma ampliação do pensamento da tecnologia de produção otimizada, pois se utiliza, em grande parte, da sua teoria. Neste estágio de evolução da técnica, Goldratt deparou-se com um problema: ele havia desenvolvido toda uma lógica de princípios que tinha como suporte um software extremamente potente, mas era necessário populizar esse conhecimento e, evidentemente, o software. Em 1984, juntamente com Jeff Cox, editou "A Meta". A genialidade desse livro está além das idéias nele contidas e reside na maneira como as mesmas são apresentadas.

Em resumo, a ênfase fundamental das idéias do autor é o alcance que ele denomina meta da organização, ou seja, ganhar mais dinheiro através de uma adequada gestão da produção. $O$ ponto focal da sua teoria é que toda a empresa, no processo de atingir a sua meta, apresenta sempre uma ou mais restrições. Se assim não fosse, a empresa teria lucro infinito.

A restrição é definida como qualquer coisa que limita um melhor desempenho de um sistema, como o elo mais fraco de uma corrente, ou ainda, alguma coisa que a empresa não tem o suficiente.

No que diz respeito às medidas de desempenho, a Teoria das Restrições propõe a estrutura conceitual abordada a seguir. Um aspecto interessante a ser observado é que ela condena o uso de medidas físicas para avaliação do desempenho, insistindo na utilização de medidas "financeiras".

\section{A META DA EMPRESA}

A meta corresponde ao propósito global da organização. Muito embora Goldratt argumente que, em última instância, quem deve e pode definir a meta da empresa são os seus proprietários, observamos que, na sua opinião, a empresa com finalidade lucrativa deve ser visualizada como uma máquina de fazer dinheiro e sua meta definida pragmaticamente como "ganhar dinheiro", tanto no presente como no futuro.

\section{MEDIDAS PARA O ALCANCE DA META}


A partir da proposição do estabelecimento da meta como objetivo maior da empresa, a Teoria das Restrições define os parâmetros que auxiliam a medição do grau de alcance da mesma. Assim, são instituídos dois medidores propriamente ditos e uma situação necessária:

- Lucro líquido

- Retorno sobre o investimento

- Fluxo de caixa

O primeiro trata de um medidor absoluto. O lucro líquido mede o quanto de dinheiro, em termos absolutos, a empresa está gerando. O lucro líquido, para Goldratt, é diferente do Lucro líquido contábil, sendo definido como ganho menos a despesa operacional.

O segundo é um medidor relativo: o retorno sobre o investimento dimensiona o esforço necessário para o alcance de um determinado nível de lucro e é definido como o lucro líquido dividido pelo inventário.

O terceiro indicador, Fluxo de Caixa, é considerado por Goldratt como sendo muito mais uma situação necessária para sobrevivência da empresa do que propriamente um medidor do alcance da meta.

As medidas para o alcance da meta estão voltadas para a medição do desempenho global da empresa.No entanto, é muito importante estabelecer, parâmetros que guiem as ações operacionais no sentido do cumprimento da meta. Goldratt denomina esses parâmetros objetos de ação como medidas operacionais globais. Evidentemente, esses parâmetros operacionais devem ser relacionados e congruentes com as unidades de medida de alcance da meta estabelecida. Assim, são definidos os seguintes parâmetros operacionais.

\section{GANHO OU THROUGHPUT}

Índice pelo qual o sistema gera dinheiro através das vendas. Mais especificamente, o ganho corresponde ao preço de venda menos o montante de valores pagos a fornecedores pelos itens relacionados com os produtos vendidos, não importando quando foram comprados. Por exemplo: valor dos materiais comprados fornecedores, comissões pagas a vendedores de externos, taxas alfandegárias, transportes externos.

\section{INVENTÁRIO}

É definido como todo dinheiro que o sistema investe na compra de coisas que ele pretende vender. Esse conceito abrange o conceito clássico de Inventário (Estoque de matérias-primas, produtos em processo, produtos acabados) e, ainda, demais ativos tais como máquinas e construções. O valor atribuído a ele corresponde somente à importância que foi paga aos fornecedores pelos itens caracterizados como inventário.

Nenhum valor agregado é atribuído; assim, todos os demais gastos existentes no processo de transformação, como a mão- de - obra, a energia elétrica e outros recursos, não se incorporam ao valor do inventário, sendo caracterizados como despesas operacionais. Nesse modelo, o inventário de Produto acabado é valorizado apenas pelo custo da matéria - prima nele contido, pago ao fornecedor.

\section{DESPESA OPERACIONAL}

É definida como todo o dinheiro que o sistema gasta para transformar o inventário em ganho. Do ponto de vista prático, o modelo considera que todo o dinheiro gasto com algo que não possa ser guardado para um uso futuro faz parte da despesa operacional. Além desses gastos, incorporam-se a essa despesa os valores de bens que faziam parte do inventário e foram utilizados ou desgastados no período (como a depreciação de máquinas). 
Os Princípios da Teoria das Restrições Sob a Ótica da Mensuração Econômica 3

\section{ANÁLISE DOS PRINCÍPIOS DA TEORIA DAS RESTRIÇÕES ATRAVÉS DA MENSURAÇÃO ECONÔMICA}

O escopo desta seção é apresentar as idéias fundamentais da teoria das Restrições no que diz respeito à otimização do processo produtivo. É interessante observar que as proposições apresentadas para essa otimização estão "amarradas" com os conceitos de ganho, inventário e despesas operacionais, e objetivam, fundamentalmente, o alcance da meta da empresa.

No processo de planejamento das atividades, tendo em vista o alcance dos seus objetivos, a Teoria de restrições pressupõe a adequada compreensão do inter-relacionamento entre dois tipos de recursos que estão normalmente presentes em todas as empresas: o recurso restritivo e o recurso não- restritivo.

O primeiro corresponde a qualquer elemento que limita o desempenho da empresa, e o segundo àquele que não limita.

Existem diversas categorias de restrições no ambiente industrial, tais como: de mercado, de capacidade, de logística, de gerenciamento e de comportamento.

As características e necessidades do mercado definem os limites do montante de ganho da empresa. Os problemas relacionados com materiais e capacidade no processo de produção são normalmente visualizados com facilidade, recebendo, geralmente, muita atenção dos gestores. As restrições de logística, gerenciamento e comportamento também existem no ambiente das empresas, porém não são usualmente reconhecidas como limitadoras do processo.

No sentido da otimização da produção, a Teoria das Restrições propõe a máxima "a soma dos ótimos locais não é igual ao ótimo total" e estabelece nove princípios básicos:

\section{1- BALANCEAR O FLUXO E NÃO A CAPACIDADE.}

A teoria das restrições advoga contra o balanceamento de capacidade e a favor de um balanceamento do fluxo de produção na fábrica. Assim, a ênfase recai sobre o fluxo de materiais e não sobre a capacidade instalada dos recursos. Isto só é possível através da identificação dos gargalos do sistema, ou seja, dos recursos que vão limitar o fluxo do sistema como um todo. A abordagem tradicional preconiza o balanceamento da capacidade dos recursos e, a partir daí, tenta estabelecer um fluxo suave, se possível contínuo.

\section{2- O NÍVEL DE UTILIZAÇÃO DE UM RECURSO NÃO-GARGALO NÃO É DETERMINADO PELO SEU PRÓPRIO POTENCIAL E SIM POR UMA OUTRA RESTRIÇÃO DO SISTEMA.}

Esse princípio determina que a utilização de um recurso não-gargalo seja parametrizada em função das restrições existentes no sistema, ou seja, pelos recursos internos com capacidades limitadas ou pela limitação de demanda do mercado.

\section{3- A UTILIZAÇÃO E ATIVAÇÃO DE UM RECURSO NÃO SÃo SINÔNIMOS.}

Esse princípio é estabelecido a partir do emprego de dois conceitos distintos: utilização e ativação. A utilização corresponde ao uso de um recurso não-gargalo de acordo com a capacidade do recurso gargalo.

A ativação corresponde ao uso de um recurso não-gargalo em volume superior à requerida pelo recurso gargalo. A ativação de um recurso mais do que suficiente para alimentar um recurso gargalo limitante, segundo o enfoque da Teoria das Restrições, não contribui com os objetivos da otimização. O fluxo (throughput) se mantém constante, limitado pelo recurso gargalo, gerando estoque que aumenta as despesas operacionais. Este princípio não é aplicado nas formas convencionais de programação de produção.

\section{4- UMA HORA PERDIDA NO GARGALO É UMA PERDIDA NO SISTEMA INTEIRO.}

Caderno de Estudos nº13, São Paulo, FIPECAFI - Janeiro a Junho/ 1996 
Qualquer tempo perdido no gargalo seja através da preparação de máquinas, da produção de unidades defeituosas, ou da fabricação de produtos não demandados pelo mercado, diminui o tempo total restrito, disponível para atender o volume throughput.

Tendo em vista que os recursos não-gargalos devem trabalhar de forma balanceada com o fluxo estabelecido pelo gargalo, a diminuição de seu tempo, provoca automaticamente uma redução de seu tempo trabalhado no sistema como um todo.

Nesse contexto, um pressuposto dos sistemas convencionais de programação de produção é que existe benefício na redução do tempo de preparação (set-up) dos recursos, sem considerar se os mesmos são recursos gargalos ou recursos não-gargalos.

A teoria das restrições advoga que só existe benefício na redução na redução dos set-ups nos recursos gargalos da produção. Assim, a programação de produção baseada nessa teoria buscar manter os lotes maiores possíveis nos recursos gargalos, minimizando tempo gasto com a preparação desses recursos e aumentando assim, a capacidade de fluxo.

\section{5- UMA HORA ECONOMIZADA ONDE NÃO É GARGALO APENAS UMA ILUSÃO.}

Conforme já mencionado no item anterior, é importante a economia de tempo com a preparação de máquinas nos recursos gargalos, que pode ser obtida com a diminuição da quantidade total das trocas de ferramentais (processando lotes maiores), ou com a da redução do tempo gasto por preparação (trocas mais rápidas). Tendo em vista que os recursos nãogargalos deverão trabalhar de acordo com o nível do gargalo, não existe nenhum destes recursos, ou seja, essa economia simplesmente estaria elevando o montante de tempo ocioso já existente.

O raciocínio poderia ser inverso: haver conveniência em usar parte do tempo ocioso para fazer um maior número de preparação produzindo lotes menores.

Os lotes menores diminuiriam o estoque em processo e as despesas operacionais, colaborando para a fluidez da produção e aumento do fluxo.

\section{6- OS GARGALOS GOVERNAM O GANHO E O INVENTÁRIO.}

A partir das considerações anteriores, é fácil observar que os gargalos determinam o fluxo do sistema, o throughput ou ganho, Além disso, também estabelecem os níveis dos estoques, pois estes são dimensionados e localizados em pontos específicos de forma que seja possível isolar os gargalos de flutuações estatísticas provocadas pelos recursos não-gargalos que os alimentam.

É preciso evitar que qualquer atraso, causado pela flutuação estatística ou por eventos aleatórios, não cause parada no gargalo, criando-se um time buffer antes dom recurso gargalo.

O time buffer corresponde a um tipo de estoque que pode ser caracterizado como um "estoque pulmão" por tempo de segurança.

\section{7- O LOTE DE TRANSFERÊNCIA NÃO PODE E MUITAS VEZES NÃO DEVE SER IGUAL AO LOTE DE PROCESSAMENTO.}

O lote de processamento diz respeito ao tratamento de lote que vai ser processado completamente em determinado recurso, antes que este seja repreparado para o processamento de outro item. O de transferência corresponde ao tamanho do lote que vai sendo transferido para uma próxima operação.

No modelo da Teoria das restrições, os lotes de processamento e de transferência não precisam ser iguais. Isso permite dividir os lotes e reduzir o tempo de passagem dos produtos de programação de produção ( como por exemplo o MRP II - Manufacturing Requirements Planning) assumem que os lotes de processamento e de transferência são iguais. 
8- O LOTE DE PROCESSAMENTO DE VER SER VARIÁVEL E NÃO FIXO.

A maioria dos sistemas tradicionais assume que o tamanho de lote deve ser o mesmo para todas as operações de fabricação do produto.Isso conduz a um problema de escolha de tamanho a ser adotado, uma vez que as características das operações individuais podem ser conduzir a um cálculo diferente. No modelo em estudo, os lotes de processamento podem variar de uma operação para outra.

\section{9- OS PROGRAMAS DEVEM SER ESTABELECIDOS, CONSIDERANDO TODAS AS RESTRIÇÕES SIMULTANEAMENTE.}

A programação da produção, ao responder questões de o quê, quanto e quando produzir, deve levar em consideração o conjunto de restrições existentes. Nesse aspecto da programação da produção, deverá ser observado o tratamento dado ao lead times, que correspondem aos tempos de ressuprimento.

Os sistemas tradicionais, inclusive o tipo MRP II, são baseados no pressuposto de que os lead times podem ser estabelecidos em função de como a produção é programada, ou seja, eles são os resultados do processo de planejamento da produção.

A seguir, desenvolvemos um exemplo de mensuração contábil com o objetivo de avaliar, sob a ótica econômica, os princípios básicos da otimização da produção.

No exemplo simplificado, temos um único produto fabricado pela empresa em dois departamentos produtivos. O produto começa a ser fabricado no departamento A (nãogargalo), que possui capacidade instalada de 1000 horas por período e o montante de $\$ 900$ de custo fixo por período. O processamento de fabricação do produto termina no departamento G, que é o gargalo da fábrica; possui a capacidade de 300 horas - máquina e apresenta o montante de $\$ 500$ de custos fixos por período. A estrutura de preços e recursos por unidade de produto é apresentada a seguir, sendo que o custo de oportunidade sobre os ativos da empresa é calculado com base na taxa de $5 \%$ ao período. As despesas fixas comuns da empresa são de $\$ 600$ por período.

\begin{tabular}{|l|l|l|l|}
\hline & Quantidade & Unitário & Total \\
\hline Preço & $1 \mathrm{u}$ & $\$ 17$ & $\$ 17$ \\
\hline Material & $2 \mathrm{u}$ & $\$ 2$ & $\$ 4$ \\
\hline $\begin{array}{l}\text { Custo variável- } \\
\text { dept. A }\end{array}$ & $2 \mathrm{hm}$ & $\$ 1$ & $\$ 2$ \\
\hline $\begin{array}{l}\text { Custo variável }- \\
\text { dept. G }\end{array}$ & $1 \mathrm{hm}$ & $\$ 4$ & $\$ 4$ \\
\hline
\end{tabular}

Analisando os princípios básicos da otimização da produção:

- Balancear o fluxo e não a capacidade

- Os gargalos governam o ganho e o Inventário

Considerando que é prioritário balancear o fluxo e não a capacidade, e que o gargalo é quem deve governar o ganho, ou seja, o volume de venda e o nível de inventário, o departamento $A$ deverá produzir de acordo com a capacidade do departamento G, ou seja, 300 unidades, permanecendo sem estoques. $O$ departamento $G$ receberá e processará as 300 unidades que serão entregues ao mercado.

\begin{tabular}{|l|l|l|l|}
\hline DEPT. A & & DEPT. G & \\
\hline Produção & $300 u$ & produção & $300 u$ \\
\hline Entrega & $300 u$ & entrega & $300 u$ \\
\hline Estoque & 0 & estoque & 0 \\
\hline
\end{tabular}

Utilizando-se os dados deste exemplo, o resultado econômico do período é demonstrado abaixo: 


\section{DEMONSTRAÇÃO DO RESULTADO}

Receita

(-) Custo do material

(-) Custo variável

Margem

(-) Custo fixo DEPT. A

(-) Custo fixo DEPT. G

(-) Despesas gerais

(-) Custo financeiro do Inventário

Resultado econômico
$\$ 5.100$

1.200

1.800

2.100

900

500

600

$\frac{-0-}{100}$

\section{- A soma dos ótimos locais ou individuais não é igual ao ótimo total}

Esta, na verdade, não é simplesmente uma regra da otimização da produção, mas poderia ser considerada a sua grande premissa.

Neste, exemplo otimizando-se individualmente os setores, o departamento A produzirá o máximo que pode, ou seja, $500 \mathrm{u}$, das quais 300u serão transferidas para o departamento $\mathrm{G}$, permanecendo $200 \mathrm{u}$ em estoque.

O departamento $\mathrm{G}$, por sua vez, produzirá 300 u, seu limite máximo.

\begin{tabular}{|l|l|l|l|}
\hline DEPT. A & & DEPT. G & \\
\hline Produção & $500 u$ & produção & $300 u$ \\
\hline Entrega & $300 u$ & entrega & $300 u$ \\
\hline Estoque & $200 u$ & estoque & 0 \\
\hline
\end{tabular}

\section{DEMONSTRAÇÃO DO RESULTADO}

Receita

(-) Custo do material

(-) Custo variável Margem

(-) Custo fixo DEPT. A

(-) Custo fixo DEPT. B

(-) Despesas gerais

(-) Custo financeiro do inventário

Resultado econômico
$\$ 5.100$

1.200

1.800

$\frac{1.800}{2.100}$

900

500

600

$\underline{60}$

$\$ 40$

Como pode ser observado, o resultado econômico foi de apenas $\$ 40$, menor que o resultado de $\$ \$ 100$ obtido seguindo-se as duas regras anteriores. O aspecto relevante, a ser considerado é que, quando os setores buscam a otimização individual, o nível de inventário aumenta, redundando em custos que prejudicam o resultado econômico global. Neste exemplo, foi mensurado o custo financeiro da estocagem, através do percentual de $5 \%$ sobre o custo direto do produto estocado no departamento $A(\$ 1.200)$.

\section{- Uma hora economizada onde não é gargalo é apenas uma miragem}

Vamos admitir que o gestor do departamento A, preocupado em aumentar a sua produtividade, consiga trabalhar duas horas além da capacidade instalada no período, produzindo 501 unidades. De qualquer forma, o departamento $\mathrm{G}$ irá receber somente 300 $\mathrm{u}$ do que precisa, permanecendo $201 \mathrm{u}$ em estoque no departamento $A$.

\begin{tabular}{|l|l|l|l|}
\hline DEPT. A & & DEPT. G & \\
\hline Produção & $501 \mathrm{u}$ & produção & $300 \mathrm{u}$ \\
\hline Entrega & $300 \mathrm{u}$ & entrega & $300 \mathrm{u}$ \\
\hline
\end{tabular}




\section{DEMONSTRAÇÃO DO RESULTADO}

$\begin{array}{lc}\text { Receita } & \$ 5.100 \\ \text { (-) Custo do material } & 1.200 \\ \text { (-) Custo variável } & \underline{1.800} \\ \text { Margem } & 2.100 \\ \text { (-) Custo fixo DEPT. A } & 900 \\ \text { (-) Custo fixo DEPT. G } & 500 \\ \text { (-) Despesas gerais } & 600 \\ \text { (-) Custo financeiro do inventário } & \underline{60.3} \\ \text { Resultado econômico } & \underline{\mathbf{\$ 3 9 . 7}}\end{array}$

Como pode ser observado na demonstração do resultado do período, fica comprovado que a hora economizada onde não é gargalo, além de ser apenas uma miragem, diminui o lucro do período através do aumento do nível do inventário. A diminuição do lucro ocorreu porque o estoque gerado pelo departamento A aumentou para 201 unidades, aumentando, portanto, o montante de custo financeiro de estocagem.

\section{- Uma hora perdida no gargalo é uma hora perdida no sistema inteiro}

Vamos admitir que, no período o departamento $G$ trabalhe uma hora a menos, produzindo, portanto, $299 \mathrm{u}$.

\begin{tabular}{|l|l|l|l|}
\hline DEPT. A & & DEPT. G & \\
\hline Produção & $500 \mathrm{u}$ & produção & $299 \mathrm{u}$ \\
\hline Entrega & $300 \mathrm{u}$ & entrega & $299 \mathrm{u}$ \\
\hline Estoque & $200 \mathrm{u}$ & estoque & $0 \mathrm{u}$ \\
\hline
\end{tabular}

\section{DEMONSTRAÇÃO DO RESULTADO}

$\begin{array}{lc}\text { Receita } & \$ 5.083 \\ \text { (-) Custo do material } & 1.196 \\ \text { (-) Custo variável } & \underline{1.794} \\ \text { Margem } & 2.093 \\ \text { (-) Custo fixo DEPT. A } & 900 \\ \text { (-) Custo fixo DEPT. G } & 500 \\ \text { (-) Despesa Gerais } & \underline{600} \\ \text { (-) Custo financeiro do Inventário } & \underline{\mathbf{6 0}} \\ \text { Resultado econômico } & \mathbb{\mathbf { 3 3 }}\end{array}$

Como pode ser observado na demonstração do resultado, o resultado da empresa diminui em \$ 7; portanto, esse é o valor da hora perdida no gargalo, que corresponde efetivamente ao valor da hora do sistema inteiro, como a seguir demonstrado:

\begin{tabular}{|l|c|}
\hline Custo fixo dept. A & $\$ 900$ \\
\hline Custo fixo do dept. G & 500 \\
\hline Despesas gerais & 600 \\
\hline Custo financeiro do inventário & 60 \\
\hline Retorno & 40 \\
\hline TOTAL & $\$ 2.100 / 300=\$ 7$ \\
\hline
\end{tabular}


Os Princípios da Teoria das Restrições Sob a Ótica da Mensuração Econômica 8

Tendo em vista que, cada unidade de produto demanda uma hora de trabalho do departamento $\mathrm{G}$, uma hora perdida nesse setor gargalo corresponde a uma unidade de produção a menos que o sistema inteiro pode gerar, equivalendo, portanto, à perda do valor da margem de contribuição unitária do produto. Observamos que foi considerado o custo financeiro do estoque de 1 peça não processada no departamento $\mathrm{G}$.

\section{- Premissa: Otimizar a utilização da capacidade dos gargalos}

Essa premissa deriva automaticamente de todas as considerações anteriores e consubstancia-se em um dos pontos basilares da teoria das restrições.

Do ponto de vista prático, a otimização dos gargalos é efetuada não se desperdiçando o tempo deles ( quando for essa a restrição), trabalhando-se todo o tempo disponível possível (como por exemplo, na hora das refeições), diminuindo-se os set-ups nos gargalos, evitando-se o reprocessamento de peças, procurando-se transferir operações e peças executadas nos gargalos para outras máquinas não-gargalos.

Se, por exemplo, o recurso restritivo for matéria-prima, deve-se utilizá-la da forma mais produtiva possível, desde o nível do projeto, planejando a sua aplicação de modo mais econômico, até o nível do consumo efetivo, seguindo os padrões preestabelecidos e minimizando as variações de rendimento de material.

Se a restrição for o mercado, deve-se buscar e aproveitar todas as possibilidades de negócio. Por outro lado, os gargalos devem trabalhar apenas no que contribuirá para 0 volume de vendas do curtíssimo prazo, ou seja, eles não devem servir para atender pedidos futuros, em detrimento de pedidos atuais.

- Definição: As práticas da contabilidade de custos ortodoxa não conduzem à otimização do resultado global da empresa

Esta definição não corresponde propriamente a um princípio da otimização de produção, porém, pode ser deduzida a partir dos demais princípios da otimização. Por outro lado, ela é um ponto focal das críticas encontradas na Teoria das restrições sobre a contabilidade de custos.

\section{MAXIMIZANDO A UTILIZAÇÃO DA CAPACIDADE DO DEPARTAMENTO A}

\begin{tabular}{|l|c|}
\hline Custos de Produção & \\
\hline Custo variável & $\$ 1.000$ \\
\hline Custo fixo & 900 \\
\hline Total & $\$ 1.900$ \\
\hline Produção & $500 \mathrm{u}$ \\
\hline Custo unitário & $\$ 3,80$ \\
\hline
\end{tabular}

UTILIZANDO A CAPACIDADE DO DEPARTAMENTO A DE ACORDO COM O FLUXO DO GARGALO G

\begin{tabular}{|l|l|}
\hline Custos de produção & \\
\hline Custo variável & $\$ 600$ \\
\hline Custo fixo & 900 \\
\hline Total & 1.500 \\
\hline Produção & $300 \mathrm{u}$ \\
\hline Custo unitário & $\$ 5,00$ \\
\hline
\end{tabular}

Observando-se os custos unitários calculados, verifica-se que, quando o departamento A trabalha a plena capacidade, produzindo $500 \mathrm{u}$, o custo unitário do produto nesse departamento é de $\$ 3,80$. Entretanto, se esse departamento trabalhar de acordo com as 
necessidades do gargalo, produzindo apenas 300 unidades, o custo unitário aumentará para $\$ 5,00$ por unidade.

O processo decisório fundamentado em informações de custos unitários calculados pelas metodologias do full cost conduz à tomada de decisões econômicas inadequadas nas empresas. Os sistemas de contabilidade de custos ortodoxos, com a utilização do custeio por absorção, incentivam os gestores departamentais à minimização de custos unitários. Por outro lado, o custeio por absorção, de forma conjugada com a utilização de padrões, estimula os gestores a diminuir a chamada variação de volume, que diz respeito ao nível de absorção de custos fixos aos produtos.

Voltando ao exemplo em pauta, o gestor do departamento A, cobrado por custos unitários totais que refletem o nível de absorção de custos fixos nos produtos, certamente produzirá o máximo que pode, ou seja, 500 unidades. Porém, esse nível de produção, como já foi demonstrado, corresponde simplesmente a uma otimização setorial em detrimento do resultado global da empresa, que é de $\$ 40$. Paradoxalmente, o melhor resultado econômico global da empresa é de $\$ 100$, exatamente no nível de produção que apresenta o maior custo unitário do produto no departamento, ou seja, \$5,00 por unidade.

\section{CONCLUSÃO}

Os princípios da Teoria das restrições apresentam lógica e racionalidade econômica, comprovada através da mensuração contábil. De fato, como demonstram os exemplos de mensuração apresentados neste trabalho, a observação dos referidos princípios pelos gestores conduz à otimização do resultado econômico da empresa.

A contabilidade de custos tradicional, utilizando o sistema de custeio por absorção e apurando os custos unitários totais dos produtos, contraria frontalmente os princípios da Teoria das restrições, conduzindo às otimizações setoriais em detrimento do lucro global da organização.

A Teoria das restrições, no bojo de suas proposições relativas às medidas de desempenho, lucro líquido, ganho, despesa operacional, propõe, fundamentalmente, um sistema de apuração de resultados baseado no método de custeio direto, há muito tempo estudado na Teoria Contábil e amplamente aplicado em sistemas de informações contábeis gerenciais, como por exemplo, no GECON - Sistema de Informação de Gestão Econômica.

\section{RESUMO}

A Teoria das restrições foi desenvolvida no campo da Administração de Produção, apresentando uma base de princípios, conceitos e procedimentos para a gestão de produção e, ao mesmo tempo, propondo um conjunto de medidas financeiras para substituir as informações geradas pela contabilidade de custos tradicional.

Neste artigo, analisamos os princípios propostos pela teoria das restrições através da mensuração econômica e comprovamos que, de fato, a observância de tais princípios conduz à otimização do lucro global da empresa.

Evidencia-se, também, o fato de que as informações geradas pela contabilidade de custos, utilizando o método de custeio por absorção não conduzem à tomada de decisões otimizadoras do lucro da empresa.

Finalmente, o trabalho evidencia o fato de que as medidas econômicas propostas pela teoria das restrições correspondem àquelas já consagradas no campo da contabilidade de custos, derivadas da utilização de um sistema de informação contábil que adota o método de custeio variável.

\section{REFERÊNCIAS BIBLIOGRÁFICAS}

BLACKSTONE JR., John H. Capacity management. Cincinnati, South Western Publishing Co., 1989. 
Os Princípios da Teoria das Restrições Sob a Ótica da Mensuração Econômica 10

FOX. Robert E. OPT vs. MRP: Thoughtware vs. software. Creative Outuput, 1985.

GOLDRATT, Eliyahu M. Computadorized Shop floor scheduling. Production Research, 1988.

IDEM. The theory of constraints. North River Press INC., Croton-on-Hudson, NY., 1990.

IDEM. Cost accounting: the number one enemy of productivty. APICS $26^{\text {th }}$ Annual International Conference Proceedings, 1983.

IDEM. The OPT substitute for cost. Executive Video Course Module 3, Programs 8-11, 1985.

GOLDRATT, Eliyahu M. \& FOX, Robert E. A corrida pela vantagem competitiva. $5^{a}$. ed. São Paulo, Educator, 1994.

GOLDRATT, Elyahu M. \& COX, Jeff. A meta. 17a. ed. São Paulo, Educator, 1994.

GOLDRATT, Elyahu M. A síndrome do palheiro: garimpando informação num oceano de dados. $2^{\mathrm{a}}$. ed. São Paulo, Educator, 1992.

GUERREIRO, Reinaldo - A teoria das restrições e o sistema de gestão econômica: Uma proposta de Integração Conceitual. São Paulo, 1995. Tese de Livre-Docência, Faculdade de Econômica, administração e contabilidade, Universidade de São Paulo.

LUCRO INFLACIONÁRIO E FLUXO DE CAIXA

Autor: Geraldo Barbieri

Professor Doutor da FEA/USP

Pesquisador da FIPECAFI 